\title{
Elevated size and body condition and altered feeding ecology of the grouper Cephalopholis argus in non-native habitats
}

\author{
Amanda L. Meyer ${ }^{1,2, *}$, Jan Dierking ${ }^{1,3, *, * *}$ \\ ${ }^{1}$ Department of Zoology, University of Hawaii at Manoa, Honolulu, Hawaii 96822, USA \\ ${ }^{2}$ Present address: Pacific Reefs National Wildlife Complex, US Fish and Wildlife Service, Honolulu, Hawaii 96850, USA \\ ${ }^{3}$ Present address: Leibniz Institute of Marine Sciences (IFM-GEOMAR), Evolutionary Ecology of Marine Fishes Group, \\ 24105 Kiel, Germany
}

\begin{abstract}
In 1956, the shallow-water grouper Cephalopholis argus was introduced from Moorea (French Polynesia), where grouper diversity (14 species) is high, to the Main Hawaiian Islands (MHI), where only 2 rare native deep-water groupers occur. In this non-native environment, the species has flourished and has become the dominant apex predator on many reefs. In the present study, a comparison of non-native populations of C. argus in the MHI with native populations in Moorea showed that mean total length (32.0 vs. $26.9 \mathrm{~cm})$, mass (722 vs. $326 \mathrm{~g})$, growth, and body condition were each significantly elevated in the MHI. In addition, while an ontogenetic shift towards larger prey occurred in both locations, it was faster and more consistent in Moorea than in the MHI. As a result, while small C. argus of comparable size in the 2 locations consumed similar-sized prey, large C. argus in Moorea consumed significantly longer and deeper-bodied prey than their counterparts in the MHI. This pattern was unrelated to the size distributions of available prey and may thus reflect stronger intra- and interspecific competition for small prey in Moorea. Although ecological release in a broader sense (i.e. a combination of predator release, parasite release, and competitive release) may play a role, the most direct explanation for the observed differences between $C$. argus in native habitats in Moorea (with many competing grouper species) and non-native habitats in the MHI (few competitors) would be competitive release (here used in the sense of benefits resulting from the reduction of interspecific competition).
\end{abstract}

KEY WORDS: Competitive release - Ecological release $\cdot$ Interspecific competition $\cdot$ Niche shift Invasive species $\cdot$ Peacock hind $\cdot$ Main Hawaiian Islands $\cdot$ Moorea (French Polynesia)

Resale or republication not permitted without written consent of the publisher

\section{INTRODUCTION}

Interspecific interactions and competition among ecologically similar species commonly affect patterns of habitat use and species abundance in areas of shared habitat (Robertson 1996). Competitive release can result from the removal of a competitor due to overexploitation, thus freeing up previously restricted resources, or the addition of a species into an environment in which it faces little interspecific competition for available resources. In either case, it can affect the growth, abundance, population structure and feeding ecology of a species (Schmitt \& Holbrook 1990, Chiappone et al. 2000, Lohrer et al. 2000). Several studies of marine fishes have documented increases in abundance and changes in habitat utilization of a species following the removal of a competitor (Schmitt \& Holbrook 1990, Robertson 1996, Dulvy et al. 2000). However, despite strong recent interest in patterns of marine invasions (e.g. Schofield 2009) few studies have looked at competitive release following the introduction to a new environment (but see Lohrer et al. 2000), and none have focused on coral reef fish. 
Due to their geographic and hydrographic isolation, the Main Hawaiian Islands (MHI hereafter) have a unique assemblage of coral reef and shore fish species, with one of the highest rates of endemism $(\sim 25 \%)$ in the world (Randall 2007). Compared to most tropical Pacific locations, several fish families are underrepresented or completely absent from the shallow inshore reefs of the MHI. Among these is the family Serranidae, specifically the subfamily Epinephelinae, or groupers (Randall 1987). In 1956, the grouper species peacock hind, Cephalopholis argus, was introduced into this environment from Moorea, French Polynesia (where it is known as 'roi') (see Fig. 1) in an attempt to create a grouper fishery (Oda \& Parrish 1981, Randall 1987). Initially introduced to the islands of Oahu and Hawaii, it has since spread to all of the MHI, and has become the dominant apex predator on many reefs (Dierking et al. 2009). Concern about potential negative effects of this - in evolutionary terms - new predation source on native Hawaiian reef fish assemblages, which have evolved without shallow water groupers, have resulted in recent investigations of the feeding ecology of $C$. argus in the MHI (Dierking \& Meyer 2009, Dierking et al. 2009). However, comparisons of the ecology of this species in native and nonnative habitats are lacking to date.

The coral reef habitats of Moorea and the MHI are similar in age and distance from the equator, but the grouper species compositions differ, with 14 native species of Epinephelinae in Moorea, but only 2 rare native deep-water grouper species, Epinephelus quernus and E. lanceolatus, in the MHI (Randall 1987). Interspecific competition for resources may therefore be less intense for Cephalopholis argus in the MHI, which may have facilitated its establishment and subsequent population increase, and its present day success. In addition, native large reef fish predators such as jacks (Carangidae) and sharks have strongly declined in the MHI since the early 20th century due to overfishing (Shomura 1987, Smith 1993, Friedlander \& DeMartini 2002, Williams et al. 2008), raising the possibility of anthropogenic priming of Hawaiian ecosystems for the successful introduction and spread of $C$. argus.

In this context, the goal of the present study was to compare morphometrics (size, body condition), population size structure, and feeding ecology (diet composition, presence and nature of ontogenetic shifts) of Cephalopholis argus in its native habitats in Moorea (i.e. the source location) and the non-native habitats in the MHI. We then analyzed these data in the context of the hypothesis that competitive release after introduction from an environment with many competitors to one with few competitors can provide advantages to a species and result in shifts in its ecological niche.

\section{MATERIALS AND METHODS}

\section{Study locations and collections}

Moorea is a small island in the South Pacific, located $19 \mathrm{~km}$ west of the island of Tahiti in French Polynesia (Fig. 1). It was the source location from where Cephalopholis argus was introduced to the MHI in 1956. C. argus individuals $\left(\mathrm{n}_{\text {total }}=166\right)$ were collected from 13 sites along the north and west coasts of Moorea in March and June of 2005. In the MHI, C. argus $\left(\mathrm{n}_{\text {total }}=304\right)$ were collected in July 2003 from 11 sites along the west coast of the island of Hawaii and 6 sites along the west, south, and east

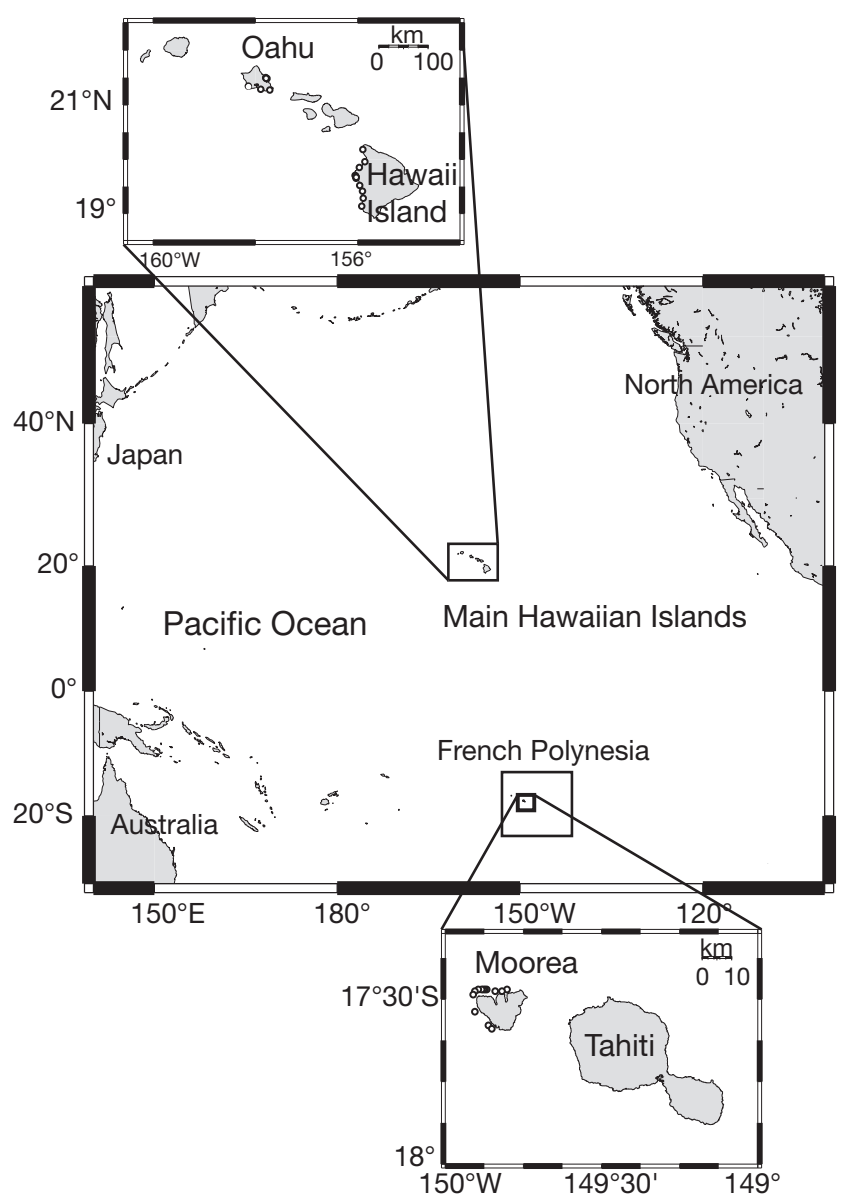

Fig. 1. Main Hawaiian Islands (MHI; the only location worldwide where Cephalopholis argus is a non-native species) and Moorea (the source location of the introduction to the MHI in 1956). Collection sites are marked by circles 
shores of the island of Oahu. All collections were conducted during daytime on the reef slope at depths between 3 and $30 \mathrm{~m}$ by SCUBA divers using spears. Speared fish were placed immediately into ziploc bags while still under water to prevent loss of stomach contents from regurgitation, which is common in C. argus (Dierking \& Meyer 2009), and were placed on ice immediately after completion of the dive.

\section{Cephalopholis argus morphometrics}

Upon return to the laboratory, the total length (TL) (to the nearest $\mathrm{mm}$ ) of all specimens and the mass (M) (to the nearest g) of Moorea and Oahu specimens were recorded. M data for the island of Hawaii (lacking due to scale failure during fieldwork) were estimated from the TL of individuals using published length-mass equations for Cephalopholis argus in the MHI (Dierking et al. 2009).

\section{Cephalopholis argus feeding ecology}

Stomachs of all 166 specimens from Moorea and of 285 specimens from the MHI were removed, opened, and classified as either empty (no prey) or full (containing prey). When stomachs were full, the TL and body depth $(\mathrm{D}$, here defined as ventral-dorsal distance at the highest point of the body) of prey items were measured to the nearest $\mathrm{mm}$. Fish prey was then identified to the family level using keys by Randall $(2005,2007)$, whereas crustacean prey was recorded but not identified to taxon. Following Hyslop (1980), numerical importance $(\% \mathrm{~N}$, defined as the number of items of one prey category divided by the total number of prey items found in all sampled stomachs $\times 100)$ and frequency of occurrence $(\% \mathrm{O}$, defined as the number of stomachs containing prey items of one category divided by the total number of stomachs that contained identifiable prey items $\times 100$ ) were calculated for all prey types.

\section{Statistical analysis}

Differences in stomach vacuity rate (i.e. prevalence of empty stomachs) and prey composition of $\mathrm{Ce}$ phalopholis argus between locations were assessed using Chi-square tests. For prey composition, we compared the importance in the diet (as measured by $\% O$ ) of (1) the broad prey categories 'fish' and 'crustacean' and (2) of the 5 most important fish families between locations. Body condition was calculated as $\log _{10}(\mathrm{M}): \log _{10}(\mathrm{TL})$ ratio (Bolger \& Connolly 1989). Differences in mass at a given TL between locations were assessed with an analysis of covariance (ANCOVA) with $\log _{10}(\mathrm{M})$ as a response variable and $\log _{10}(\mathrm{TL})$ as a covariate; in the MHI, only groupers from Oahu were used due to lack of M data from the island of Hawaii. Predator-prey size relationships (prey TL and prey D vs. C. argus TL) were tested by linear regression, and differences in predator-prey size relationships between Moorea and the MHI were assessed using ANCOVA with prey size as a response variable and $C$. argus size as a covariate. The interaction term Location $\times C$. argus size was included to assess differences in the slopes of the regression of prey TL vs. C. argus TL. Finally, differences in mean prey size of same-sized $C$. argus individuals (grouped in 2 size categories chosen based on overlap of size distributions in Moorea and the MHI, small: $\leq 26.0 \mathrm{~cm}$; large: 32.0 to $36.0 \mathrm{~cm}$ ) from the 2 locations were assessed with $t$-tests. For the analyses, data from the sample sites within the 2 locations Moorea and the MHI were pooled, based on the consideration that sample sizes for individual sites were too low for the purposes of a dietary or morphometric study. This is illustrated by dietary data, which will differ even between sites with similar reef fish assemblages if sample sizes are insufficient to reach an asymptote in cumulative prey curves. For $C$. argus in the MHI, this point is approached only at sample sizes >170 (Dierking et al. 2009), whereas sample sizes per site in the present study were on average an order of magnitude smaller. We considered pooling justified as preliminary tests found no differences in predator-prey size relationships among sites within each location, in the occurrence of fish and crustacean prey in the diet, and in vacuity rates between islands within the MHI. For C. argus body size, small but significant differences occurred among sites within locations, but in absolute terms, site means were nevertheless similar within locations compared to the differences between locations (all site means in Moorea $<27.0 \mathrm{~cm}$ vs. all means in the MHI $>29.5 \mathrm{~cm}$ ). Minitab 14 was used for all statistical analyses, with results considered significant at $\mathrm{p}<0.05$.

\section{RESULTS}

\section{Differences in morphometrics}

Cephalopholis argus in the MHI were on average significantly longer (mean $\pm 1 \mathrm{SD}, \mathrm{TL}=32.0 \pm 6.7 \mathrm{~cm}$ 
vs. $26.9 \pm 5.3 \mathrm{~cm} ; 2$ sample $t$-test, $\mathrm{df}=409, t=9.02, \mathrm{p}<$ $0.001)$ and heavier ( $M=722 \pm 487 \mathrm{~g}$ vs. $326 \pm 198 \mathrm{~g}$; 2 sample $t$-test, $\mathrm{df}=439, t=12.41, \mathrm{p}<0.001$ ) than in Moorea (Fig. 2a,b). Body mass at a given length as measure of the condition of $C$. argus individuals was also significantly higher in the MHI than in Moorea independently of the size of individuals (ANCOVA with TL as covariate, testing for location as the main effect; $\left.\mathrm{df}=1,274 ; F_{\text {Location }}=320.7, \mathrm{p}<0.001\right)$. While size ranges for Moorea and MHI C. argus did not completely overlap due to the lower sizes in Moorea compared to the MHI, body condition was also consistently higher when considering only the overlapping range (Fig. 3).

\section{Differences in feeding ecology}

The stomach vacuity rate in Cephalopholis argus was significantly higher in Moorea, where $63.3 \%$ (104 of 166) analyzed stomachs were empty, than in the MHI, where only $44.9 \%$ (126 of 285 ) stomachs were empty (Chi-square test, $\mathrm{df}=1, \chi^{2}=14.1, \mathrm{p}<$ 0.001). Fish represented the most important prey type (as measured by \%O) in both locations, with crustaceans making up the remainder of the diet (Table 1). The overall importance of fish and crustacean prey did not differ significantly between locations (Chi-square test, $\mathrm{n}_{\text {total }}=238, \mathrm{df}=1, \chi^{2}=0.73, \mathrm{p}=$ 0.39 ). In contrast, when considering only the fish component on the family level, diet composition differed strongly (Table 1) and significantly (Chi-square test including the 5 most important families in each location, $\left.\mathrm{n}_{\text {total }}=104, \mathrm{df}=1, \chi^{2}=34.0, \mathrm{p}<0.001\right)$. Over-

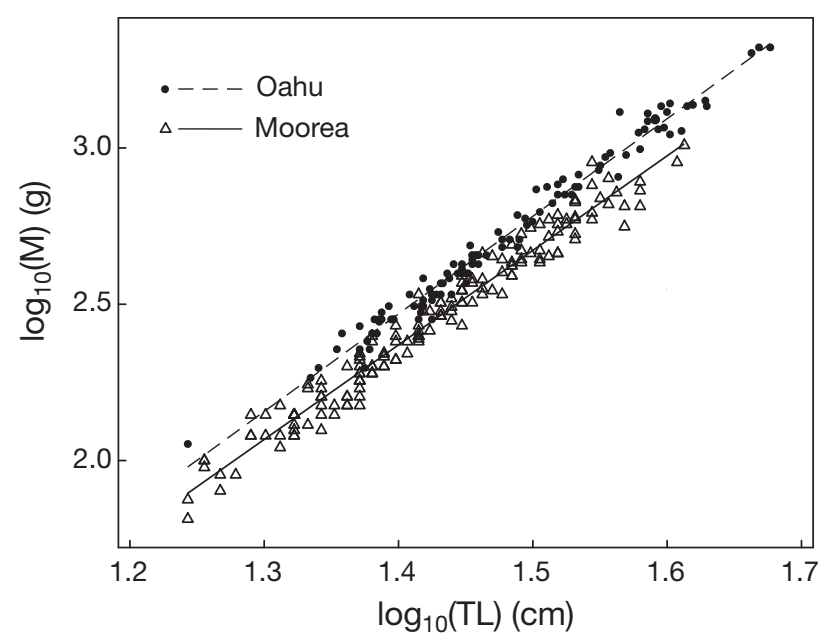

Fig. 3. Cephalopholis argus. Relationships of $\log _{10}$ (mass, M) and $\log _{10}$ (total length, TL) (with mass at length being a measure of body condition) for C. argus from the island of Oahu (Main Hawaiian Islands) ( $\mathrm{n}=110)$ and Moorea $(\mathrm{n}=165)$, with regression lines for each region

all, 10 fish families were identified from 62 full $C$. argus stomachs in Moorea, vs. 19 families from 159 full stomachs in the MHI.

Cephalopholis argus in both the MHI and Moorea showed a significant increase in prey TL with an increase in own (predator) TL (linear regression; MHI: $\mathrm{n}$ $=135, \mathrm{p}<0.001, \mathrm{r}^{2}=0.05$; Moorea: $\mathrm{n}=24, \mathrm{p}<0.001$, $\mathrm{r}^{2}=0.42$ ). However, the increase in prey $\mathrm{TL}$ with C. argus TL was more consistent (i.e. higher amount of variability explained by the regression, see $r^{2}$ values above) and significantly more pronounced (i.e. steeper slope: $\mathrm{ANCOVA}, \mathrm{df}=1,159, F_{\text {Location } \times \text { C.argus } \mathrm{TL}}=$ 9.06, $\mathrm{p}=0.003$ ) in Moorea than in the MHI (Fig. 4a).
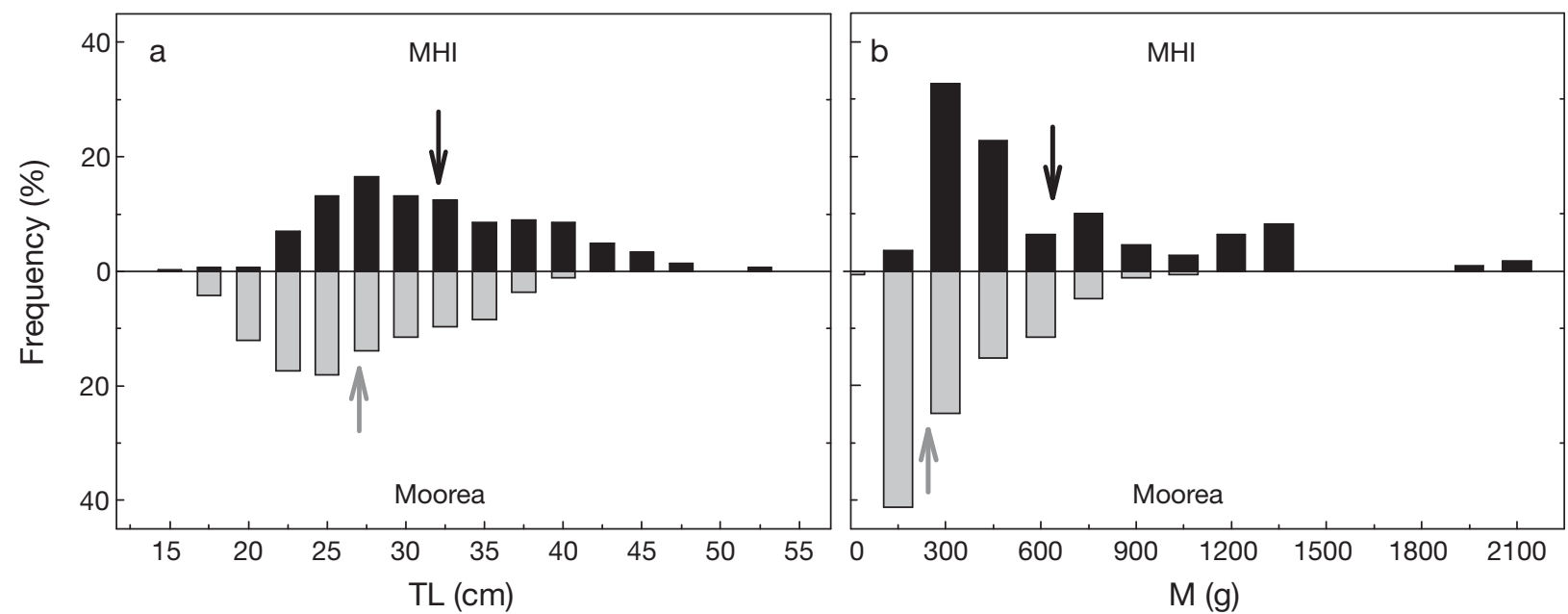

Fig. 2. Cephalopholis argus. Comparison of the size frequency distributions of $C$. argus in the Main Hawaiian Islands (MHI; $\mathrm{n}=304$ ) and Moorea ( $\mathrm{n}=166)$. (a) Total length (TL); (b) Mass (M). Arrows indicate mean values for TL and M at each location 
Similarly, prey D was significantly positively correlated with $C$. argus TL in both the MHI and Moorea (linear regression; MHI: $\mathrm{n}=134, \mathrm{p}<0.001, \mathrm{r}^{2}=0.08$;
Moorea: $\left.\mathrm{n}=20, \mathrm{p}<0.001, \mathrm{r}^{2}=0.54\right)$, with a more consistent and significantly faster (ANCOVA, $\mathrm{df}=1,154$, $F_{\text {Location } \times \text { C.argus } \mathrm{TL}}=8.97, \mathrm{p}=0.003$ ) increase of prey D with TL of $C$. argus in Moorea (Fig. 4b). As a result of the faster shift, while small $C$. argus (TL $<27 \mathrm{~cm}$ ) in Moorea consumed prey of similar TL and $\mathrm{D}$ as same-sized $C$. argus in the MHI ( $t$-test $, \mathrm{df}=19, t=0.62, \mathrm{p}=0.62)$, larger individuals (TL 32 to $36 \mathrm{~cm}$ ) in Moorea consumed significantly longer $(t$-test; $\mathrm{df}=8, t=-2.63, \mathrm{p}=0.03)$ and deeper-bodied ( $t$-test; $\mathrm{df}=6, t=-3.71$, $p=0.01)$ prey than their same-sized counterparts. In summary, ontogenetic shifts to larger prey occurred both in non-native habitats in the MHI and native habitats in Moorea, but the shift towards larger prey was significantly faster and more consistent in Moorea.

\section{DISCUSSION}

Competitive release plays an important role in both the terrestrial (Moreno et al. 2006, Trewby et al. 2008) and aquatic realm (Werner \& Hall 1976, Robertson 1996, Persson \& Lars-Andres 1999, Lohrer et al. 2000), but case studies assessing this mechanism in biological invasions by marine fishes are lacking to date. The grouper Cephalopholis argus faces

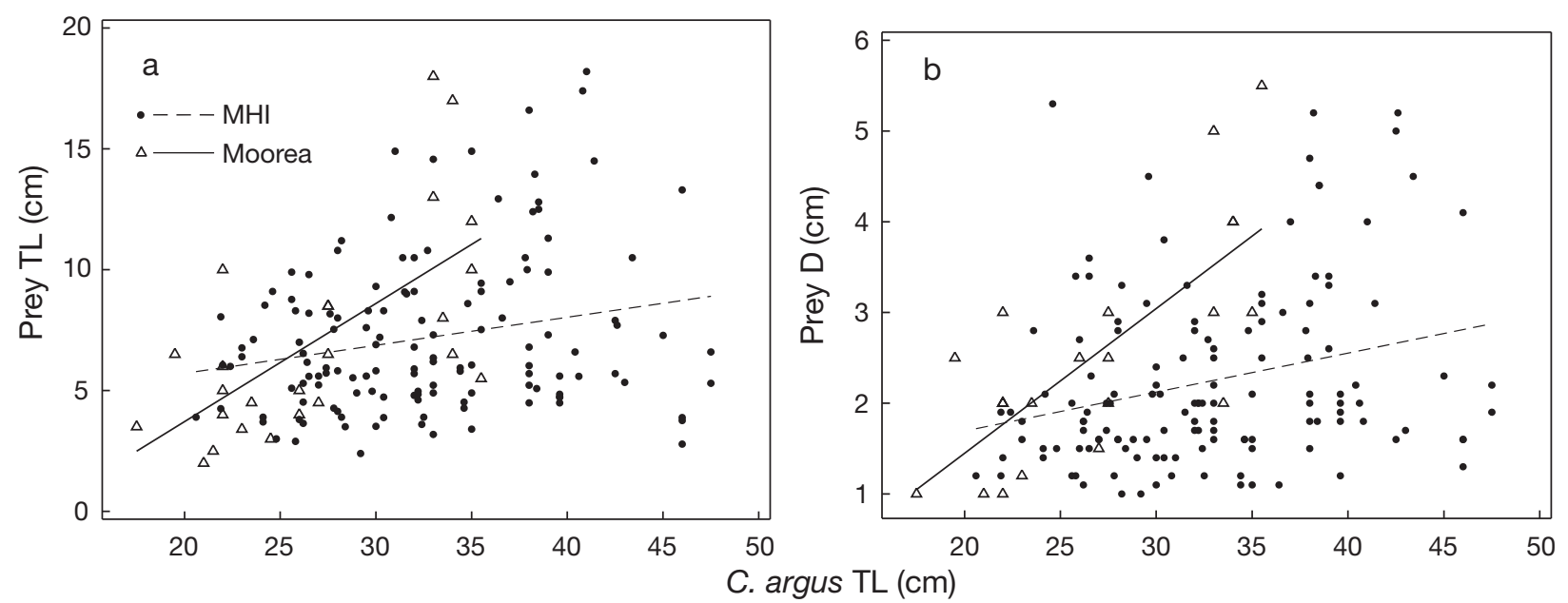

Fig. 4. Cephalopholis argus. Relationship of the size of $C$. argus and the size of prey consumed in the Main Hawaiian Islands (MHI) and Moorea. (a) Prey total length (TL) vs. TL of C. $\operatorname{argus}_{\text {; }}$ (b) Prey body depth (D) vs. TL of C. $\operatorname{argus.} \mathrm{MHI}$ : $\mathrm{n}_{\mathrm{TL}}=135$, $\mathrm{n}_{D}=134 ;$ Moorea: $\mathrm{n}_{\mathrm{TL}}=24, \mathrm{n}_{D}=20 . y$-values of data points represent the size of individual prey items 
resource competition from 14 shallow-water grouper species in its native habitat in Moorea (Meyer 2008), but little or no competition from native groupers and other large piscivores in its non-native habitat in the MHI (Dierking et al. 2009). Despite the limitations of using only 2 locations (Moorea as source and the MHI as only location worldwide where $C$. argus is non-native), this situation presented a unique opportunity to assess niche shifts following the introduction of a reef fish. Here, we first address differences in $C$. argus morphometrics and feeding ecology between the source and non-native location, before discussing if and how these patterns fit the concept of competitive release.

\section{Differences in morphometrics}

There were several indications that Cephalopholis argus individuals were performing better in the nonnative habitats in the MHI. Most notably, this was supported by the much higher mean and maximum sizes in the MHI compared to Moorea, with large individuals (>40 $\mathrm{cm}$ or $1000 \mathrm{~g}$ ) common in the MHI but exceedingly rare in Moorea. As dive teams, sampling methodology, habitat type, depth, and time of day of sampling were similar in both locations, it is unlikely that these differences were methodological artifacts. The notion of differences in performance was further supported by the significantly higher condition index of C. argus in the MHI. Importantly, growth data for $C$. argus in Moorea and the MHI indicate that the larger sizes attained in the MHI were not due to a longer life span of individuals, but to higher growth rates, with individuals of the same age being larger in the MHI than in Moorea $(\mathrm{H}$. Choat unpubl. data).

\section{Differences in feeding ecology}

The significantly lower stomach vacuity rate of Cephalopholis argus in the MHI compared to Moorea indicated that feeding success of $C$. argus was higher in the MHI. Importantly, C. argus feeds diurnally in both locations (Meyer 2008, Dierking et al. 2009), which excludes the possibility of artifacts related to sampling fish at different points in their activity period. Most other broad patterns in feeding ecology were similar in the 2 locations and fit patterns described for C. argus elsewhere. Specifically, the importance of fish and to a lesser degree, crustaceans, and absence of cephalopods in the diet is typical for the species (Shpigel \& Fishelson 1989, Dierking et al. 2009). Furthermore, on the family level, the wide dietary range in both native (10 fish families in 62 full stomachs) and non-native (19 families in 159 full stomachs) habitats indicated that C. argus was a generalist predator, which is also the case in Madagascar (Harmelin-Vivien \& Bouchon 1976) and the Red Sea (Shpigel \& Fishelson 1989) and is typical for groupers (Parrish 1987). Accordingly, the different dietary range in the 2 locations was likely related to the different number of analyzed full stomachs (a function of overall sample size and vacuity), considering that cumulative prey curves plotting the number of unique taxa identified against the number of analyzed stomachs for C. argus in the MHI (from Dierking et al. 2009) predict 11 and 18 families for our sample sizes, which are close to the observed values in Moorea and the MHI, respectively.

To interpret the observed family-level differences in dietary composition of Cephalopholis argus between Moorea and the MHI, it is important to consider that reef fish assemblages in the habitats in which $C$. argus was sampled differ markedly between the MHI (based on data from Dierking et al. 2009) and Moorea (based on unpubl. data by T. Lison de Loma). For example, the Acanthuridae are the most important family in the MHI (36\% of the total fish assemblage by $\% \mathrm{~N}$ ) but only take 4 th rank in Moorea $(5.9 \%)$, where the Pomacentridae clearly dominate assemblages with $61 \%$ of total abundance (vs. $32 \%$ in the MHI). Considering that prey availability directly influences prey composition of generalist predators (Parrish 1987), divergent prey fish assemblage compositions provide a straightforward explanation for taxonomic differences in the diet of C. argus from the 2 locations. At the same time, the abundance of taxa in the diet and in the wild was not directly proportional, as demonstrated by the much higher importance of Scaridae in the diet (Table 1) than their abundance in the wild in both locations $(1.6 \%)$ would suggest. This agrees with findings by Beukers-Stewart \& Jones (2004) and Dierking et al. (2009) that groupers are not purely opportunistic but show prey electivity, likely at least in part related to divergent vulnerability of taxa to predation.

The ontogenetic shifts towards larger prey with increasing body size of Cephalopholis argus in both native and non-native habitats in the present study mirror similar shifts in other piscivorous species, including the serranids Plectropomus leopardus (Kingsford 1992, St. John 1999) and Epinephelus quoyanus (Connell 1998). This shift is commonly 
attributed to the increase of mouth and stomach volume and gape size with body size, which allows the utilization of a wider range of prey (St. John 1999). At the same time, the significantly faster and more consistent shift towards longer and deeper-bodied prey in Moorea observed here revealed an interesting difference between our locations. This pattern was also expressed in the consistent focus on larger prey by large $C$. argus in Moorea but not in the MHI, where they consumed a wide range of prey sizes including small and shallow-bodied prey. For example, the smallest prey consumed by a $35 \mathrm{~cm} \mathrm{C}$. argus measured $3 \mathrm{~cm}$ in D in Moorea, whereas individuals of the same size commonly consumed prey as small as $1 \mathrm{~cm}$ in the MHI.

A straightforward explanation for these patterns would exist if large groupers in the MHI consumed small prey simply because large prey were unavailable or rarer than in Moorea. However, 2 lines of evidence rule out this possibility: (1) large groupers in the MHI actually prefer small to larger prey fish, i.e. they feed on large fish less often than their abundance on reefs would suggest (Dierking et al. 2009), and (2) mean reef fish size in the habitats in which Cephalopholis argus was sampled was in fact lower in Moorea $(5.47 \pm 5.81 \mathrm{~cm} ; \mathrm{T}$. Lison de Loma unpubl. data) than in the MHI $(9.1 \pm 5.17 \mathrm{~cm}$; Dierking et al. 2009). An alternative explanation is provided by divergent strength of interspecific competition between the locations. In particular, if competition for small prey is high, it should be beneficial for large predators to exploit larger prey as soon as their gape size allows. Meyer (2008) observed frequent competition for food and aggressive interactions between C. argus and C. urodeta, Epinephelus fasciatus, E. hexagonatus, and E. merra in Moorea. The rapid shift to larger prey may thus reflect a strategy to reduce competition with smaller con-specifics and other small groupers, whereas the weaker shift in the MHI could relate to lower competition. In turn, the possibility to exploit a wide prey size range could account for the lower stomach vacuity and increased feeding success over time for superior body condition and growth rates in non-native habitats of $C$. argus in the MHI.

\section{Indications for competitive release}

Interspecific competition occurs most frequently among ecologically similar species with high overlap in diet and microhabitat use (Schoener 1983), and has a strong potential to affect the abundance and ecology of the species involved (e.g. Werner \& Hall 1976, Trewby et al. 2008). Shifts in microhabitat and resource use following competitive release have been documented for many species, e.g. Stegastes planifrons on reefs in the Caribbean (Robertson 1996). A good example of competitive release following a species invasion is the Asian shore crab Hemigrapsus sanguineus, which increased its dietary range and vertical spatial distribution in invaded habitats (Lohrer et al. 2000), but similar examples for marine fishes are lacking to date. In the present study, considering the much lower species diversity and abundance of large shallow-water reef piscivores in the MHI compared to native habitats in Moorea, competitive release of Cephalopholis argus in the non-native habitats offered a possible explanation for the clear and significant differences discussed above.

It should be noted that, in principle, differences between (1) the ecosystems, (2) the prey fish assemblages, and (3) the fishing pressure in the 2 locations could also contribute to the observed patterns. However, several lines of evidence speak against a major role of these alternatives and thus strengthen the case for competitive release. Regarding (1), the coral reefs of Moorea and the $\mathrm{MHI}$ are similar in distance from the equator, longitude, age, water temperature, and other physical characteristics (Galzin 1987, Planes \& Lecaillon 1998, Friedlander \& DeMartini 2002), which should limit the influence of these parameters on morphometrics or feeding success of Cephalopholis argus between locations. Moreover, differences that are present between the systems do not seem likely to explain the observed differences in C. argus. In particular, if primary productivity in the Moorea system was lower than in the MHI, it might have contributed to the smaller size of $C$. argus compared to the $\mathrm{MHI}$, but it is in fact higher (Legendre et al. 1988, Boucher et al. 1998, Ondrusek et al. 2001). In addition, differential productivity would not account for the more rapid and consistent switch to larger prey with increasing size of $C$. argus in Moorea. Similarly, regarding (2), while differences in fish assemblage composition between locations, e.g. related to the high rate of endemism in the $\mathrm{MHI}$ and location in the Pacific, likely contributed to the divergent fish prey composition (see 'Differences in feeding ecology' above), they cannot account for the superior body condition and growth of C. argus in the MHI. Overall fish abundance would seem a more likely candidate but is also ruled out, as the overall number of reef fish species are similar for the MHI (129 species from 20 families) and Moorea (135 spe- 
cies from 27 families), and more importantly, as reef fish densities are generally higher in Moorea (263 to 549 ind. $100 \mathrm{~m}^{-2}$ vs. 92 to 132 ind. $100 \mathrm{~m}^{-2}$ for the MHI) (Galzin 1987, Adjeroud et al. 2002, Friedlander and DeMartini 2002, Randall 2007). Regarding (3), it is important to stress that due to the high risk of ciguatera fish poisoning from $C$. argus consumption both in the MHI (Dierking \& Campora 2009) and Moorea (Meyer 2008), the species has experienced very low fishing pressure and has not been sold commercially in notable numbers over the past decades. In addition, due to concerns about negative effects of C. argus predation on native fishes, removal efforts have been conducted in the $\mathrm{MHI}$ in recent years, but with one small-scale exception, this commenced only after the end of our collections in 2003. In any case, the removed numbers of $C$. argus (tens to hundreds of individuals) are low compared to total abundance, which Dierking (2007) estimated to be over 50000 ind. for the west coast of the island of Hawaii alone, and thus unlikely to influence the size distribution of the population.

A final alternative to consider is the occurrence of founder effects (Mayr 1954) at the time of the introduction, i.e. if a genetically and phenotypically distinct subset of the source population had founded the MHI population. Of particular interest is whether large individuals were specifically chosen for the introduction, as it could explain larger sizes in the MHI. However, accounts of the introduction (Randall 1987, J. Randall pers. comm.) stress that mainly small individuals were captured in Moorea because more would fit into the live-well of the vessel used for the transport to the MHI. Nevertheless, genetic differences between the MHI and Moorea population, e.g. due to genetic drift during the initial population bottleneck (Hartl 2000) cannot be fully excluded, and a genetic assessment would be of interest not only to complement our study but also from an evolutionary perspective.

Alternative or complementary ecological mechanisms that have been proposed to contribute to the success of species invasions include predator release, i.e. lower predation pressure on an invader in its new habitat (Wolfe 2002), and parasite release, i.e. lower parasite load of an invader in its new habitat (Torchin et al. 2001). While predator release could explain higher densities of Cephalopholis argus in nonnative habitats, it is less consistent with enhanced feeding success, condition, and growth. Conversely, parasite escape may offer an explanation for higher condition and growth, but fails to account for higher feeding success and different ontogenetic shifts.
Thus, while a role of ecological release in a broader sense (i.e. a combination of predator-, parasite-, and competitive release) is possible, competitive release provides the most straightforward explanation for the observed patterns.

\section{CONCLUSION}

The comparison of Cephalopholis argus in the MHI (the only region in which this species has been introduced, and home to only 2 rare native deep-water groupers) and Moorea (the source of the introduction to the MHI, and home to 14 grouper species) provided a rare opportunity to assess aspects of ecological theory that were formulated primarily in the terrestrial realm in the aquatic domain of coral reefs. Most importantly, C. argus in non-native habitats in the MHI showed significantly higher feeding success and different feeding patterns than in its native habitats, and was characterized by larger size, enhanced condition, and faster growth. While ecological release in a broader sense (i.e. release from predators, parasites, and competition) may play a role, competitive release provides the most direct explanation for our findings. Further studies on the parasite load in native and non-native $C$. argus populations and on levels of predation on this species in the 2 locations would help to further assess this question. From an evolutionary perspective, genetic data to assess the occurrence of founder effects during the introduction would also be of great interest. Overall, the case study of the $C$. argus introduction demonstrates the potential for niche shifts (i.e. ecological and morphological differences) between populations of the same species in native and non-native habitats, and implicates the mechanism of competitive release as a potential factor influencing the success of biological invasions.

Acknowledgements. We are grateful to C. Birkeland, J. Parrish, S. Conant, R. Kinzie, I. Williams, B. Bowen, and to 3 anonymous reviewers for suggestions that improved this paper. Furthermore, we thank T. Clark, S. Fujimoto, R. Robertson, W. Walsh, S. Cotton, B. Carmen, S. Poujade, and Q. Mauguit for help with field collections, and Y. Chancerelle, P. Ung, and T. Lison de Loma of the Centre de Recherches Insulaires et Observatoire de l'Environnement (CRIOBE) for their support while in Moorea. H. Choat, T. Molea, and R. Pears graciously granted us access to unpublished age data for fish in this study, and T. Lison de Loma to unpublished data on the taxonomic and size composition of fish assemblages in Moorea. J. Randall provided valuable background on sizes of $C$. argus that were chosen for the introduction to the MHI. Funding was in part provided by 
the National Oceanic and Atmospheric Administration under award no. NA05NOS4261157 to the Hawaii Coral Reef Initiative, and the University of Hawaii Arts and Sciences Advisory Council. Personal financial support for A.L.M. was provided by the National Science Foundation Graduate Research Fellowship Program, and for J.D. by the Fulbright Program.

\section{LITERATURE CITED}

Adjeroud M, Augustin D, Galzin R, Salvat B (2002) Natural disturbances and interannual variability of coral reef communities on the outer slope of Tiahura (Moorea, French Polynesia): 1991 to 1997. Mar Ecol Prog Ser 237: 121-131

Beukers-Stewart BD, Jones GP (2004) The influence of prey abundance on the feeding ecology of two piscivorous species of coral reef fish. J Exp Mar Biol Ecol 299: 155-184

Bolger T, Connolly PL (1989) The selection of suitable indices for the measurement and analysis of fish condition. J Fish Biol 34:171-182

Boucher G, Clavier J, Hily C, Gattusoe JP (1998) Contribution of soft-bottoms to the community metabolism (primary production and calcification) of a barrier reef flat (Moorea, French Polynesia). J Exp Mar Biol Ecol 225: 269-283

Chiappone M, Sluka R, Sealey K (2000) Groupers (Pisces: Serranidae) in fished and protected areas of the Florida Keys, Bahamas and North Caribbean. Mar Ecol Prog Ser 198:261-272

> Connell SD (1998) Patterns of piscivory by resident predatory reef fish at One Tree Reef, Great Barrier Reef. Mar Freshw Res 49:25-30

> Dierking J, Campora CE (2009) Ciguatera in the introduced fish Cephalopholis argus (Serranidae) in Hawaii, and implications for fishery management. Pac Sci 63:193-204

Dierking J, Meyer AL (2009) Prey regurgitation in the grouper Cephalopholis argus. J Appl Ichthyol 25:600-602

Dierking J, Williams ID, Walsh WJ (2009) Diet composition and prey selection of the introduced grouper species peacock hind (Cephalopholis argus) in Hawaii. Fish Bull 107:464-476

Dierking J (2007) Effects of the introduced predatory fish Cephalopholis argus on native reef fish populations in Hawaii. PhD Dissertation, University of Hawaii at Manoa, Honolulu

Dulvy NK, Metcalfe JD, Glanville J, Pawson MG, Reynolds JD (2000) Fishery stability, local extinctions, and shifts in community structure in skates. Conserv Biol 14:283-293

Friedlander AM, DeMartini EE (2002) Contrasts in density, size, and biomass of reef fishes between the northwestern and main Hawaiian Islands: the effects of fishing down apex predators. Mar Ecol Prog Ser 230:253-264

Galzin R (1987) Structure of fish communities of French Polynesian coral reefs. I. Spatial scales. Mar Ecol Prog Ser 41:129-136

Harmelin-Vivien M, Bouchon C (1976) Feeding behaviour of some carnivorous fishes (Serranidae and Scorpaenidae) from Tuléar (Madagascar). Mar Biol 37:329-340

Hartl DL (2000). A primer of population genetics, 3rd edn. Sinauer Associates, Sunderland, MA

Hyslop EJ (1980) Stomach content analysis - a review of the methods and their application. J Fish Biol 17:411-429
Kingsford MJ (1992) Spatial and temporal variation in predation on reef fishes by coral trout (Plectropomus leopardus, Serranidae). Coral Reefs 11:193-198

> Legendre L, Demers S, Delesalle B, Harnois C (1988) Biomass and photosynthetic activity of phototrophic picoplankton in coral reef waters (Moorea Island, French Polynesia). Mar Ecol Prog Ser 47:153-160

> Lohrer AM, Whitlatch RB, Wada K, Fukui Y (2000) Home and away: comparisons of resource utilization by a marine species in native and invaded habitats. Biol Inv 2:41-57

Mayr E (1954). Change of genetic environment and evolution. In: Huxley J, Hardy AC, Ford EB (eds) Evolution as a process. Allen \& Unwin, London, p 57-180

Meyer A (2008) An ecological comparison of Cephalopholis argus between native and introduced populations. $\mathrm{PhD}$ Dissertation, University of Hawaii at Manoa, Honolulu

> Moreno RS, Kays RW, Samudio R Jr (2006) Competitive release in diets of ocelot (Leopardus pardalis) and puma (Puma concolor) after jaguar (Panthera onca) decline. J Mammal 87:808-816

Oda D, Parrish JD (1981) Ecology of commercial snappers and groupers introduced to Hawaiian reefs. Proc Int Coral Reef Symp, Manila, p 59-67

- Ondrusek ME, Bidigare RR, Waters K, Karl DM (2001) A predictive model for estimating rates of primary production in the subtropical North Pacifc Ocean. Deep-Sea Res II 48:1837-1863

Parrish JD (1987) The trophic biology of snappers and groupers. In: Polovina JJ, Ralston S (eds) Tropical snappers and groupers: biology and fisheries management. Westview Press, Boulder, CO, p 405-463

Persson A, Lars-Andres H (1999) Diet shift in fish following competitive release. Can J Fish Aquat Sci 56:70-78

$>$ Planes S, Lecaillon G (1998) Consequences of the founder effect in the genetic structure of introduced island coral reef fish populations. Biol J Linn Soc 63:537-552

Randall JE (1987) Introduction of marine fishes to Hawaiian Islands. Bull Mar Sci 41:490-502

Randall JE (2005) Reef and shore fishes of the South Pacific. New Caledonia to Tahiti and the Pitcairn Islands. University of Hawaii Press, Honolulu

Randall JE (2007) Reef and shore fishes of the Hawaiian Islands. Sea Grant College Program, University of Hawaii, Honolulu

Robertson RD (1996) Interspecific competition controls abundance and habitat use of territorial Caribbean damselfishes. Ecology 77:885-899

Schmitt RJ, Holbrook SJ (1990) Population responses of surfperch released from competition. Ecology 71:1653-1665

Schoener TW (1983) Field experiments on interspecific competition. Am Nat 122:240-285

Schofield PJ (2009) Geographic extent and chronology of the invasion of non-native lionfish (Pterois volitans [Linnaeus 1758] and P. miles [Bennett 1828]) in the Western North Atlantic and Caribbean Sea. Aquat Inv 4: 473-479

Shomura RS (1987) Hawaii's marine fishery resources: yesterday (1900) and today (1986). National Marine Fisheries Service, Southwest Fisheries Center, Honolulu Laboratory. Administrative report H-87-21, Honolulu, HI

> Shpigel M, Fishelson L (1989) Food habits and prey selection of three species of grouper from the genus Cephalopholis (Serranidae: Teleostei). Environ Biol Fishes 24: 67-73

Smith MK (1993) An ecological perspective on inshore fish- 
eries on the Main Hawaiian Islands. Mar Fish Rev 55: 34-49

St. John J (1999) Ontogenetic changes in the diet of the coral reef grouper Plectropomus leopardus (Serranidae): patterns in taxa, size and habitat of prey. Mar Ecol Prog Ser 180:233-246

Torchin ME, Lafferty KD, Kuris AM (2001) Release from parasites as natural enemies: increased performance of a globally introduced crab. Biol Inv 3:333-345

Trewby ID, Wilson GJ, Delahay RJ, Walker N and others (2008) Experimental evidence of competitive release in

Editorial responsibility: John Choat,

Townsville, Queensland, Australia sympatric carnivores. Biol Lett 4:170-172

Werner EE, Hall DJ (1976) Niche shifts in sunfishes: experimental evidence and significance. Science 191:404-406

Williams ID, Walsh WJ, Schroeder RE, Friedlander AM, Richards BL, Stamoulis KA (2008) Assessing the importance of fishing impacts on Hawaiian coral reef fish assemblages along regional-scale human population gradients. Environ Conserv 35:261-272

> Wolfe LM (2002) Why alien invaders succeed: support for the escape-from-enemy hypothesis. Am Nat 160: 705-711

Submitted: May 5, 2010; Accepted: August 8, 2011

Proofs received from author(s): October 7, 2011 